\title{
Real-time PCR detection of Plasmodium directly from whole blood and filter paper samples
}

\author{
Brian J Taylor ${ }^{1 \dagger}$, Kimberly A Martin ${ }^{1 \dagger}$, Eliana Arango², Olga M Agudelo², Amanda Maestre ${ }^{2}$ and \\ Stephanie K Yanow ${ }^{3,4^{*}}$
}

\begin{abstract}
Background: Real-time PCR is a sensitive and specific method for the analysis of Plasmodium DNA. However, prior purification of genomic DNA from blood is necessary since PCR inhibitors and quenching of fluorophores from blood prevent efficient amplification and detection of PCR products.

Methods: Reagents designed to specifically overcome PCR inhibition and quenching of fluorescence were evaluated for real-time PCR amplification of Plasmodium DNA directly from blood. Whole blood from clinical samples and dried blood spots collected in the field in Colombia were tested.

Results: Amplification and fluorescence detection by real-time PCR were optimal with 40X SYBR ${ }^{\circledR}$ Green dye and $5 \%$ blood volume in the PCR reaction. Plasmodium DNA was detected directly from both whole blood and dried blood spots from clinical samples. The sensitivity and specificity ranged from $93-100 \%$ compared with PCR performed on purified Plasmodium DNA.

Conclusions: The methodology described facilitates high-throughput testing of blood samples collected in the field by fluorescence-based real-time PCR. This method can be applied to a broad range of clinical studies with the advantages of immediate sample testing, lower experimental costs and time-savings.
\end{abstract}

\section{Background}

The availability of sensitive diagnostic tools for malaria is critical to ensure appropriate treatment for patients and to preserve the lifespan of effective anti-malarials. In the field, the most common tools for malaria diagnosis are microscopy and rapid detection tests (RDTs), which are performed directly from the blood sample. Molecular methods that amplify and detect Plasmodium DNA using specific reagents and platforms, such as real-time PCR, provide far greater sensitivity, but are not yet usable at the point-of-care. However, these methods have important applications in clinical research studies that involve the analysis of blood samples collected in the field, including genotyping parasite populations and monitoring drug resistance, genetic characterization of vaccine candidates, anti-malarial efficacy trials and surveillance programs [1-3].

\footnotetext{
* Correspondence: yanow@ualberta.ca

† Contributed equally

${ }^{3}$ School of Public Health, University of Alberta, Edmonton, Canada

Full list of author information is available at the end of the article
}

The performance of molecular tests largely depends on the quality of the parasite DNA. Highly purified DNA requires laborious sample processing and costly reagents, kits or equipment, whereas cruder extraction methods often produce DNA that is insufficiently pure for downstream testing. The presence of PCR inhibitors from the blood, such as haemoglobin, reduces the efficiency of the molecular reaction and compromises sensitivity [4,5]. However, the discovery of DNA polymerases that are resistant to PCR inhibition enables DNA to be amplified from blood without prior extraction. For malaria, this was recently demonstrated using the Phusion ${ }^{\mathrm{TM}}$ enzyme which amplifies DNA by nested PCR directly from dried blood spots on filter papers [6].

One of the major advances in molecular diagnostics is the integration of fluorescence-based detection of DNA in real-time PCR. This poses a new challenge to direct PCR from blood as fluorophores are quenched in the presence of haemoglobin. Amplification can be achieved, but the product is not detected. One approach to overcome the quenching effect uses inhibitor-resistant Taq mutants in combination with an enhancer cocktail

\section{C) Biomed Central}


within the PCR master mix for optimal amplification and fluorescence detection $[7,8]$. With these reagents, real-time PCR can be performed even with $25 \%$ blood volume in the PCR reaction [8]. The usefulness of this method was evaluated for the direct detection of Plasmodium DNA by real-time PCR from raw patient samples and from dried blood spots collected in the field.

\section{Methods}

\section{Samples}

DNA for optimization of the PCR from blood was purified from Plasmodium falciparum 3D7 in vitro culture [9] using DNAzol according to the manufacturer's protocol (Invitrogen Life Technologies, Carlsbad, USA). Parasite gDNA was spiked into negative blood. Negative samples $(\mathrm{n}=7)$ were collected from healthy volunteers with no recent history of travel to malaria endemic areas. Blood samples from febrile patients with suspected malaria $(n=67)$ were obtained from the Provincial Laboratory for Public Health in Edmonton, Canada, between 2008 and 2011 following diagnosis by microscopy and routine testing by real-time PCR [10]. Of these samples, 57 were smear positive with parasitaemias ranging from $<0.01 \%$ to $9.2 \%$; 25 of the samples had a parasitaemia $<0.1 \%$. Microscopy was performed in regional laboratories and parasitaemias were determined from the analysis of thin smears. Two of the smear-negative samples were positive by RDT. Samples from refugees $(n=25)$ were collected within two weeks of arrival in Canada as part of a separate research study. All subjects were asymptomatic for malaria. Samples were first screened by microscopy and tested retrospectively by real-time PCR as reported [11]. Of the total clinical samples tested, the following species were detected by real-time PCR: Plasmodium falciparum $(\mathrm{n}=39)$, Plasmodium vivax $(\mathrm{n}=23)$, Plasmodium ovale $(\mathrm{n}=9)$, and Plasmodium malariae $(\mathrm{n}=$ 2). Blood samples were collected in EDTA or citrate tubes, stored at $-20^{\circ} \mathrm{C}$ and thawed at $4{ }^{\circ} \mathrm{C}$ prior to testing. Genomic DNA from Plasmodium knowlesi was obtained from MR4.

Dried blood spots were prepared on 3 MM paper (Whatman) from blood samples collected from patients who attended the malaria clinic at Puerto Libertador, in Cordoba, Colombia between 2008 and 2010. Filter papers were dried at ambient temperature in the field, shipped to Medellín and stored in plastic bags at $-20^{\circ} \mathrm{C}$. Positive patients were symptomatic for malaria and had infections ranging from 120-39,920 parasites/ $\mu \mathrm{L}$ (median value of 4763 parasites $/ \mu \mathrm{L}$ ) by microscopy performed on thick smears in the field. To confirm the presence of Plasmodium DNA, DNA was extracted using Chelex ${ }^{\circledR}$ 100 (Sigma) and tested by nested PCR according to the protocol described by Snounou et al [12]. Of the 48 samples, 20 were positive for Plasmodium falciparum, 18 were positive for Plasmodium vivax and 10 were negative by microscopy and nested PCR. For real-time PCR, $1.5 \mathrm{~mm}$ diameter blood spots were excised from filter papers using a sterilized hole punch. Spots were tested directly or soaked first for 3 minutes in sterile distilled water at $50^{\circ} \mathrm{C}$. This study was approved by the Health Research Ethics Board at the University of Alberta and Comité de Bioética, Sede de Investigación Universitaria, Universidad de Antioquia (Acta 07-32126) in Colombia.

\section{Real-time PCR and melt curve analysis from blood}

PCR was performed as described [8] in a $20 \mu \mathrm{L}$ reaction containing 1× PCR Enhancement Cocktail (PEC-1), 1× Omni Klentaq buffer, $0.3 \mu \mathrm{L}$ of OKT polymerase (all from DNA Polymerase technologies, St. Louis, USA), $200 \mu \mathrm{M}$ dNTPs, $0-40 \times$ SYBR $^{\circledR}$ Green (Invitrogen Life Technologies, Carlsbad, USA), and blood at $5-10 \%$ of the total reaction volume. To detect the $18 \mathrm{~S}$ rRNA gene from all species of Plasmodium, primers reported by Kamau et al [13] (forward 5'-GCTCTTTCTTGA TTTCTTGGATG-3' and reverse 5'-AGCAGGTTAAGATCTCGTTCG-3') were used at $200 \mathrm{nM}$ concentrations. Published primers were used for species-specific real-time PCR detection of Plasmodium falciparum (5' PLF, 3'FAR; [14]), Plasmodium vivax, Plasmodium ovale and Plasmodium malariae (rVIV, rOVA, and rMAL primers; [12,15]). A new Plasmodium ovale reverse primer (Po260; 5'-GGCAAATGCTTTCGCAGTTGT-3') with reduced primer-dimer interactions was substituted for the rOVA reverse primer. Primers were used at $400 \mathrm{nM}$ except the Plasmodium malariae set, which was used at $800 \mathrm{nM}$. Real-time PCR was performed on the ABI 7500 Fast system (Applied Biosystems, USA) with the following conditions: $95^{\circ} \mathrm{C}$ for $10 \mathrm{~min}, 40$ cycles of $95^{\circ} \mathrm{C}$ for $30 \mathrm{sec}, 58^{\circ} \mathrm{C}$ for $1 \mathrm{~min}$ and $72^{\circ} \mathrm{C}$ for $1 \mathrm{~min}$. This was followed by the default dissociation cycle for melt curve analysis.

All samples were tested in triplicate. For whole blood samples, the baseline was set to cycles 3-15 and the threshold was set to 20,000 fluorescence units. Samples were considered negative if the cycle threshold $(\mathrm{Ct})$ value was greater than 35 or if the melt curve did not align with the positive control. For dried blood spots, the baseline was set to 5-15 and the threshold was set to 250,000 to overcome the high background fluorescence from the filter paper itself. The amplification curves generated were sometimes shallow with some variability among replicates. Samples were considered positive when at least two of the three replicates had amplification curves that crossed the threshold before cycle 35 and had the expected melt curve profile. Panel samples were tested in a blind fashion. 


\section{Results}

\section{Optimization of fluorescence detection from blood}

A titration of SYBR ${ }^{\circledR}$ Green dye was tested to determine the optimal concentration for detection of Plasmodium DNA directly from blood. PCR master mix with final concentrations of $10 \times, 20 \times$ and $40 \times$ SYBR $^{\circledR}$ Green was added to blood spiked with gDNA from Plasmodium falciparum 3D7. Two blood volumes were tested: $5 \%$ or $10 \%$ of the PCR reaction volume (Figure 1). Amplification was detected at all three concentrations of SYBR ${ }^{\circledR}$ Green but there was less variation in the replicates with the $40 \times \mathrm{SYBR}^{\circledR}$ Green concentration (Figure 1, left panels).

The melt curve profiles were also affected by the concentration of $\mathrm{SYBR}^{\circledR}$ Green in the reaction. With increasing concentrations of dye, peak heights increased, thereby improving detection of the PCR product (Figure 1 , right panels). At $40 \times \mathrm{SYBR}^{\circledR}$ Green, the melt curves were most consistent for the different blood volumes and had the highest peak heights. The fluorescence in the negative control (uninfected blood) was negligeable at this concentration. In subsequent experiments, 40x SYBR $^{\circledR}$ Green and $5 \%$ blood volume were selected as the optimal reaction conditions.

\section{Detection of Plasmodium from clinical samples}

The reaction conditions were next assessed on whole blood samples from patients infected with malaria. Blood was added directly to the PCR reaction mix and amplified by real-time PCR. For each sample, the blood was tested with the screening primers to detect all species of Plasmodium. Examples of amplification and melt curves for each species, including blood spiked with gDNA from Plasmodium knowlesi, are shown in Figure 2. To evaluate the sensitivity and dynamic range of the assay, gDNA isolated from a patient sample infected with Plasmodium falciparum (9.2\% parasitaemia) was serially diluted and spiked into uninfected blood (Figure 3). Amplification was detected in triplicate reactions across a range of 5 log dilutions with product confirmation by melt curve analysis. Based on the $\mathrm{Ct}$ values from the serial dilutions, the efficiency of the PCR directly from blood was calculated to be $84 \%$.

In a second set of experiments, blood was tested with primers specific for Plasmodium falciparum, Plasmodium vivax, Plasmodium ovale and Plasmodium malariae. Amplification with primers specific to the four major species of Plasmodium identified the species directly from blood (Figure 4). The melting temperature values (Tm) for each species differ due to the varying sizes of the PCR products for each reaction. Non-specific amplification was observed at later cycles in the negative control with the primer sets for Plasmodium falciparum and Plasmodium vivax but these products were clearly distinguished from the specific product by melt curve analysis. Furthermore, the curves from these non-specific products crossed the threshold after cycle 35 and would therefore be called negative.

\section{Detection from dried blood spots}

An important application of this methodology is the direct amplification of Plasmodium DNA by real-time PCR from dried blood spots collected in the field. To evaluate this, blood spots were prepared from a clinical sample infected with Plasmodium falciparum (1.4\% parasitaemia) and tested under the same reaction conditions used for whole blood with the Plasmodium screening primers. Spots excised from filter paper were either directly added to the PCR master mix or washed briefly in water. Amplification of Plasmodium DNA was detected in both the neat and washed filter papers, although the amplification curves for the neat samples had lower background and tighter replicates compared with the washed samples (Figure 5A). The melt curves for the neat and washed samples were very similar (Figure $5 \mathrm{~B}$ ). Given these results, neat blood spots were used in the subsequent validation experiments.

\section{Validation of the assay for Plasmodium}

The sensitivity and specificity of this method for whole blood and blood spots was determined using blind panels of clinical samples (Table 1). For whole blood, the panel consisted of 100 samples: 67 from patients with suspected clinical malaria, 25 from asymptomatic refugees from endemic countries, 7 from volunteers with no history of malaria, as well as one sample with genomic DNA from Plasmodium knowlesi spiked into uninfected blood. These samples had been tested previously by real-time PCR performed on purified DNA using the method implemented at the Alberta ProvLab for malaria confirmation. This method uses a TaqMan probe and a different set of primers to screen for Plasmodium [10]. According to the results by real-time PCR on purified DNA, 64/67 samples from patients with suspected clinical malaria were positive, $9 / 25$ of the asymptomatic refugee samples were positive, and the Plasmodium knowlesi sample was positive, giving a total of 74 positive and 26 negative samples in the panel. In the real-time PCR test directly from blood samples, 69 samples were positive and 31 were negative for Plasmodium (Table 1). The overall concordance of the realtime PCR results from blood and purified DNA was $95 \%$. Five positives were undetected, resulting in an assay sensitivity of $93 \%$ and a specificity of $100 \%$.

Microscopy results were available for 95/100 samples, 57 of which were positive with parasitaemias ranging 

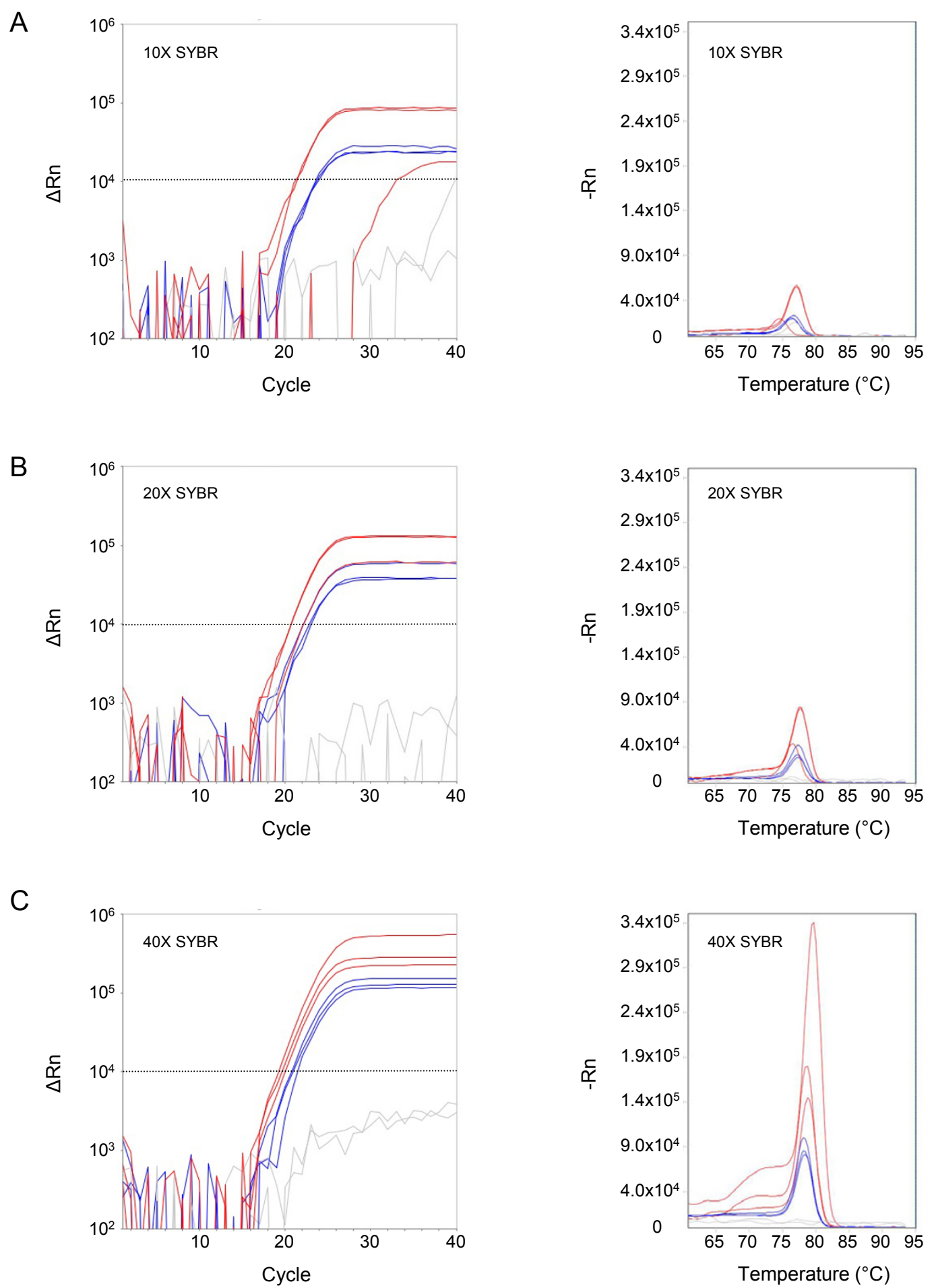

Figure 1 Optimization of reagents for real-time PCR. Amplification curves (left panels) and melt curves (right panels) from Plasmodium

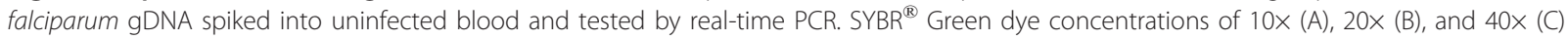
were tested with $5 \%$ (red) and 10\% (blue) volumes of blood in the PCR reaction. Uninfected blood serves as a negative control (gray). The stippled line marks the threshold for the amplification curves. Samples were run in triplicate. 


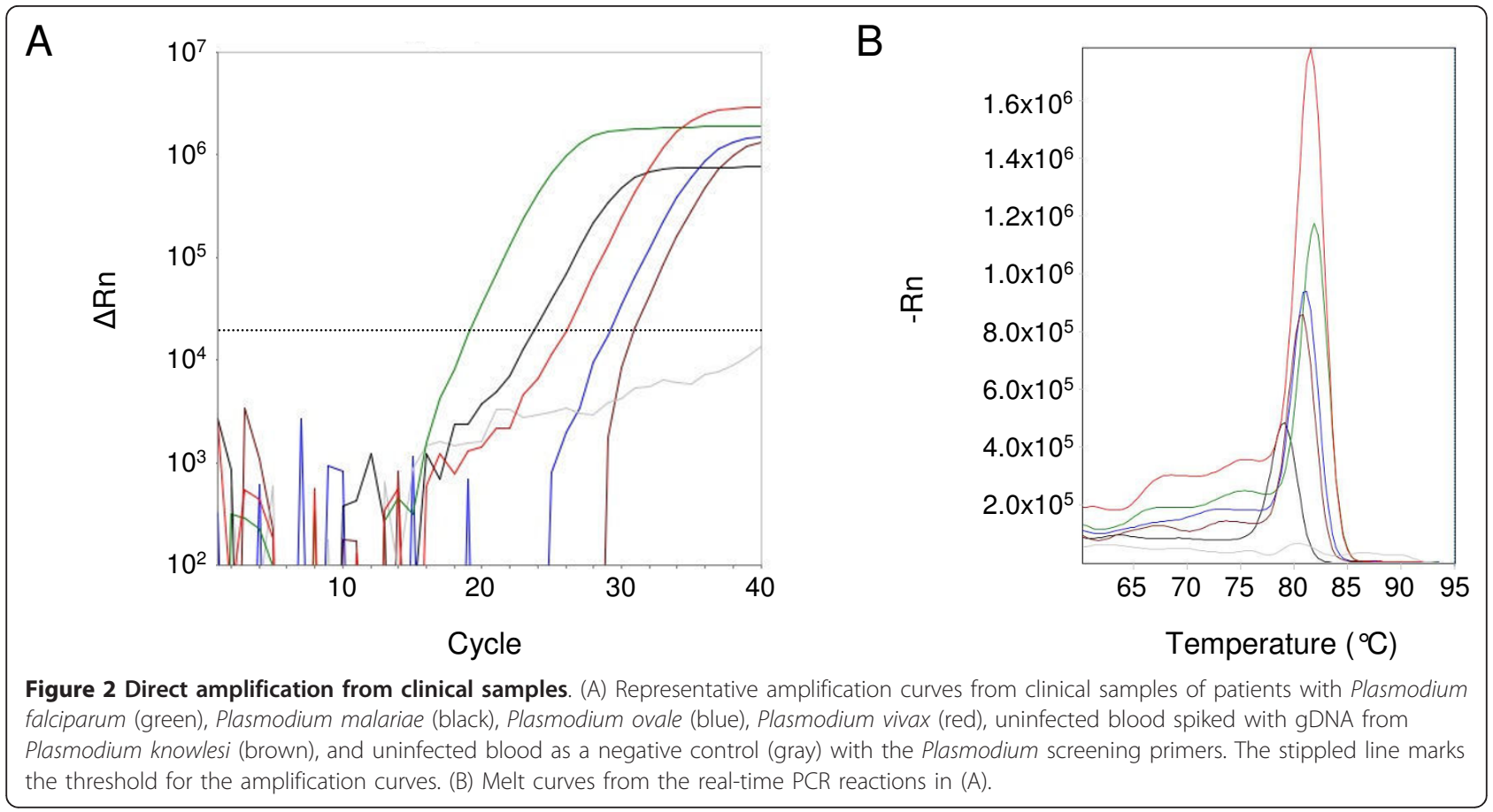

from $<0.01 \%$ to $9.2 \%$. Of these, 25 samples had an undetermined parasitaemia $<0.1 \%$. Four of the false negative samples in the direct blood panel were from asymptomatic refugees and the fifth was from an acute malaria sample. All five samples were negative by microscopy.
For dried blood spots, patient samples collected in the field in Colombia were tested in a blind panel that consisted of 38 positives and 10 negatives (Table 1). The identity of the samples was confirmed by nested PCR on purified gDNA extracted from the blood spots performed in Colombia using the method of Snounou et al

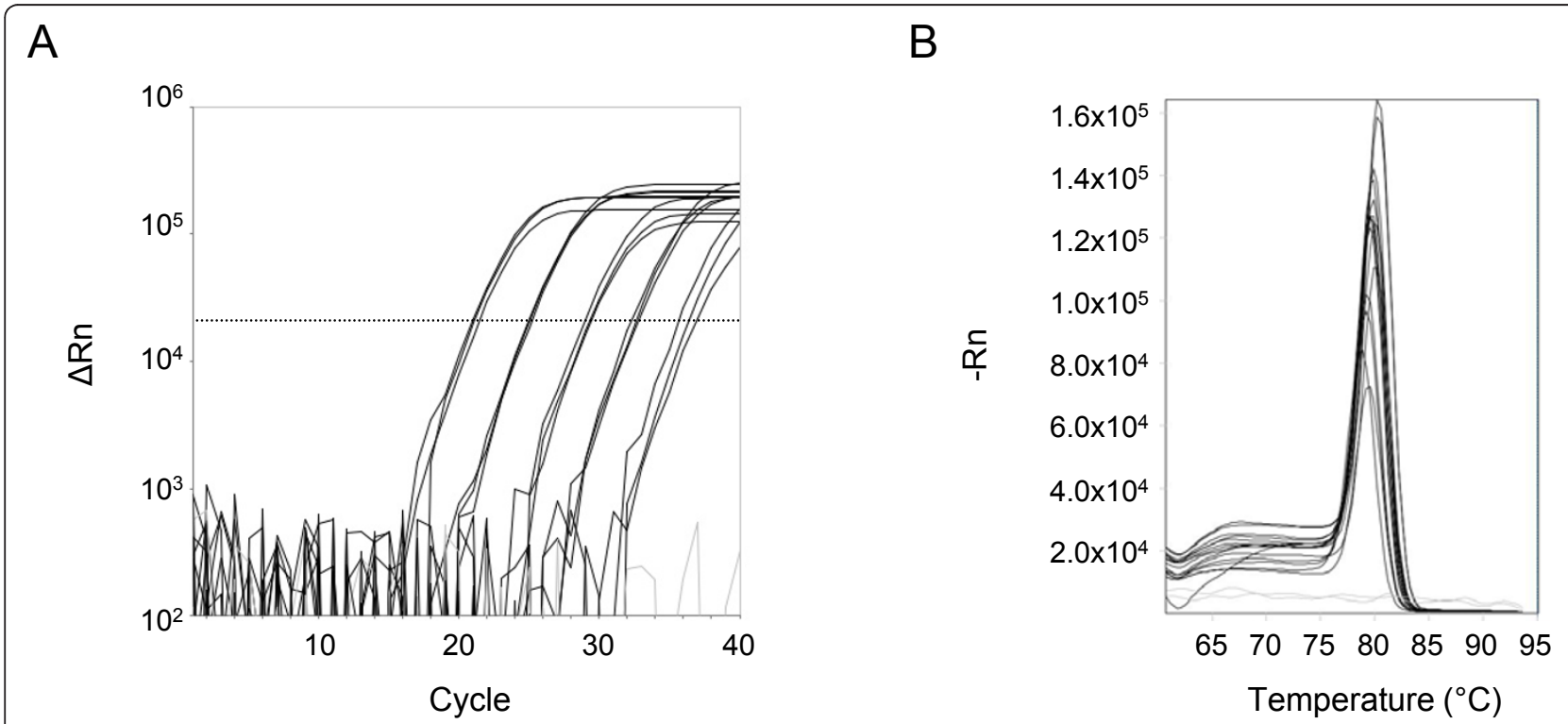

Figure $\mathbf{3}$ Template dilution in blood. Genomic DNA from a patient sample with Plasmodium falciparum was serially diluted ten-fold in water and spiked into whole blood for direct PCR. Amplification curves (A) and melt curves (B) of reactions performed in triplicate using the Plasmodium screening primers. Uninfected blood served as the negative control (gray). The stippled line marks the threshold for the amplification curves. 


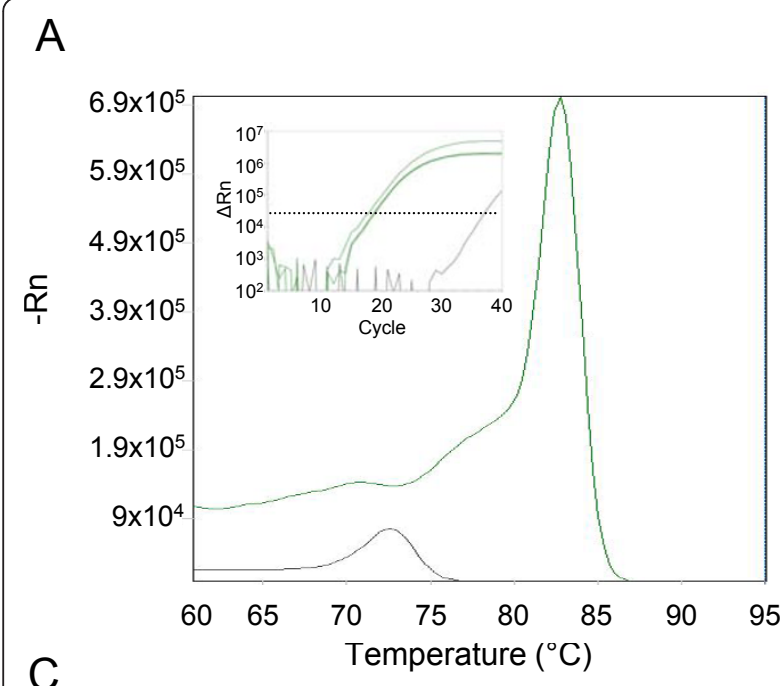

B
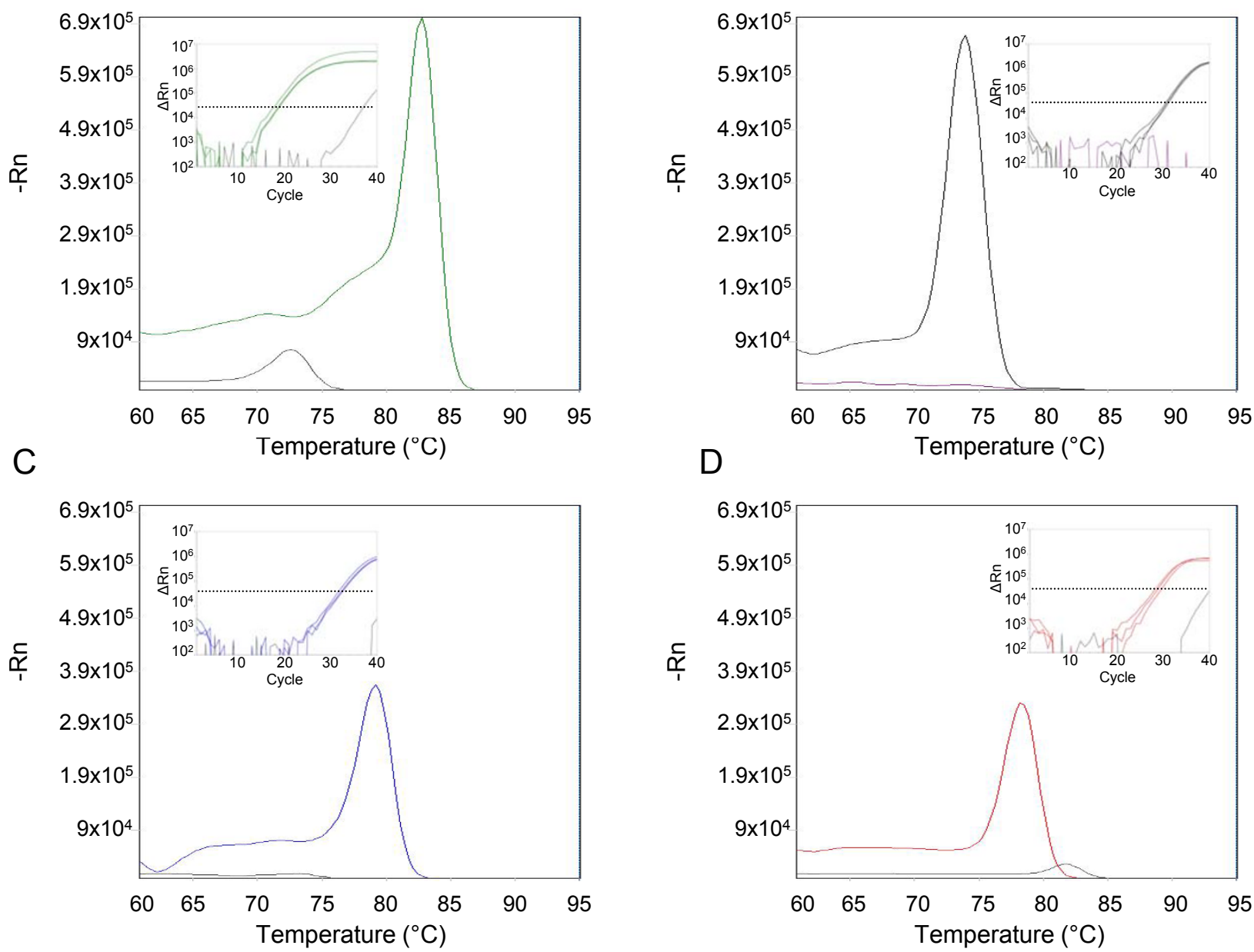

Figure 4 Direct species identification from clinical samples. (A-D) Representative melt curves and amplification curves (inset) from clinical samples with Plasmodium falciparum (A), Plasmodium malariae (B), Plasmodium ovale (C), and Plasmodium vivax (D) following real-time PCR with species-specific primers. Amplification curves are shown in triplicate but single melt curves are shown for clarity. Negative controls (gray) are from uninfected blood. The stippled line marks the threshold for the amplification curves.

[12]. The panel was tested by adding the filter paper spots directly into the real-time PCR master mix. The concordance of the assay with nested PCR on purified DNA was $100 \%$. The sensitivity and specificity of the assay were also $100 \%$.

\section{Discussion}

This report describes a methodology for DNA amplification directly from blood that is compatible with fluorescence detection by real-time PCR. Although this method cannot be used directly in the field, it facilitates the analysis of blood samples collected in field studies. Clinical trials on antimalarial or vaccine efficacy and prevalence or surveillance studies are just a few examples of applications of this test for high throughput analysis of blood samples. Either blood spots or whole blood samples can be transported to the lab and immediately tested by real-time PCR without the need for DNA extraction.

This method is particularly suited to studies seeking a rapid confirmation of malaria. The sensitivity is similar to real-time PCR performed on purified DNA and specificity is achieved through primer design to reduce nonspecific amplification. At the Alberta ProvLab, malaria diagnosis is confirmed by a TaqMan real-time PCR assay that uses a previously published primer set for the Plasmodium screening reaction [16]. The primers from this assay were initially tested in the assay described here for real-time PCR from blood. Although amplification of Plasmodium DNA was achieved with these primers with good sensitivity, sporadic non-specific amplification was observed in the negative controls. Use 
B

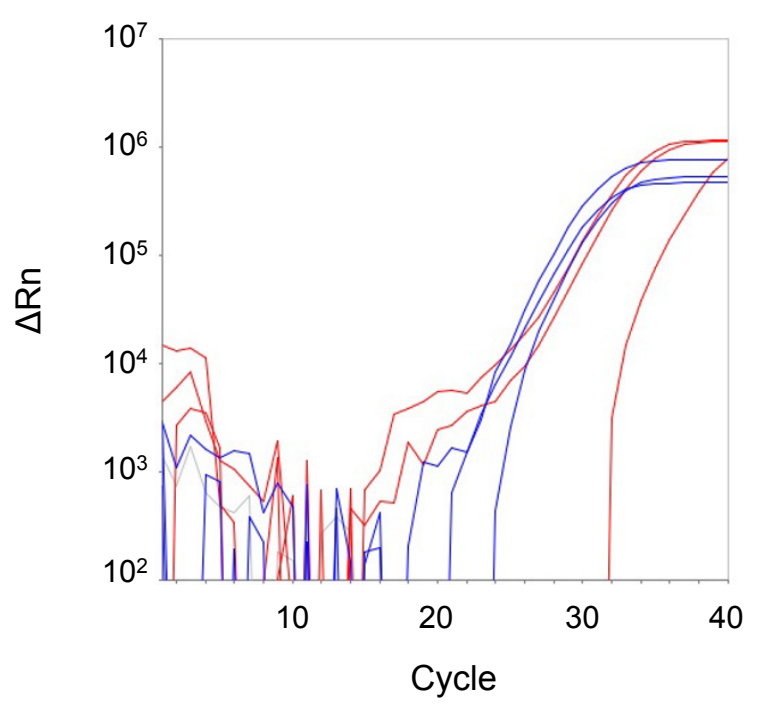

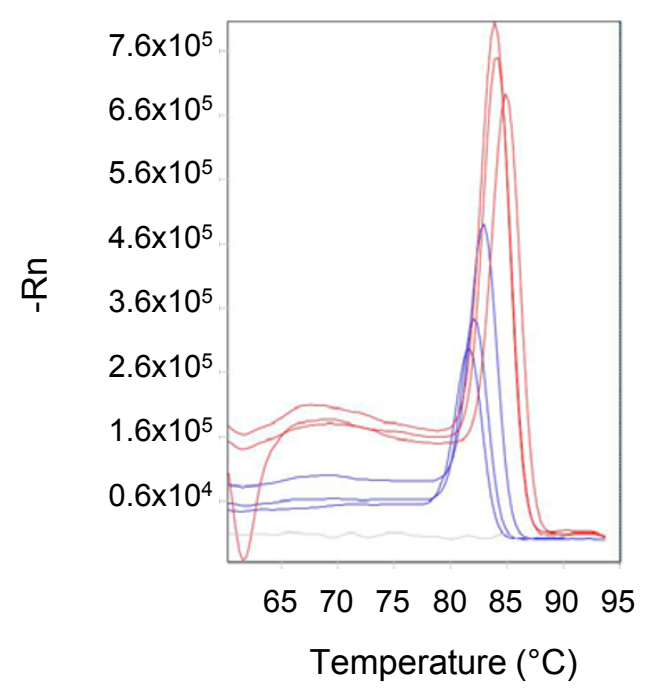

Figure 5 Real-time PCR from dried blood spots. Amplification curves (A) and melt curves (B) from DNA amplified directly from dried blood spots with the Plasmodium screening primers. Filter papers spotted with blood from a single patient sample infected with Plasmodium falciparum were added directly to the PCR master mix (blue) or washed first (red). Filter papers spotted with uninfected blood and added directly to the master mix serve as the negative control (gray). Samples were tested in triplicate. of the primers recently published by Kamau et al. [13] reduced the formation of non-specific products. For some of the species identification reactions, improvements to the primer design may further reduce non-specific products that are detected as very late amplification curves. Furthermore, primers can be designed to produce amplicons with different melting curves for each species which would enable the species to be identified in a single multiplex reaction and further reduce the cost per test.

In general, the background fluorescence in this assay is higher than in other real-time PCR assays; the high concentration of SYBR ${ }^{\circledR}$ Green required to overcome the quenching effect from the blood results in higher background fluorescence and the threshold was set at 20,000 or greater for these assays. With blood spots, fluorescence from the filter paper itself resulted in even higher background. Therefore, preliminary testing with blank filter papers and spots of uninfected blood is

Table 1 Validation of real-time PCR from blood using blind clinical samples

\begin{tabular}{llllll}
\hline & & \multicolumn{2}{l}{$\begin{array}{l}\text { Raw blood* } \\
(\mathbf{n}=\mathbf{1 0 0})\end{array}$} & \multicolumn{2}{l}{$\begin{array}{l}\text { Dried blood spotst } \\
(\mathbf{n}=\mathbf{4 8})\end{array}$} \\
\hline \multirow{3}{*}{ Purified DNA } & Pos & Neg & Pos & Neg \\
& Pos & 69 & 5 & 38 & 0 \\
& Neg & 0 & 26 & 0 & 10 \\
\hline
\end{tabular}

*Confirmed by real-time PCR according to Shokoples et al [10]

tConfirmed by nested PCR according to Snounou et al [12] highly recommended to define the Tm and expected melt curve for a positive sample relative to background. Once this is established, the interpretation of results is straight-forward. Another important consideration is that the real-time PCR must be performed in tubes and not capillaries. Preliminary testing in capillaries on the LightCycler instrument from whole blood samples failed to generate amplification curves. It is hypothesized that during the course of the PCR, dried blood accumulates along the walls of the capillaries and blocks the emission of fluorescence.

In addition to the detection of Plasmodium DNA in blood, the reagents for direct PCR can also support the detection of other blood-borne pathogens. These reagents have previously been used to detect herpes simplex virus 2 and other viruses spiked into blood [8]. In malaria-endemic countries, the diagnosis of nonmalarial causes of fever is critical to prevent morbidity and mortality, particularly from bacterial infections. A recent meta-analysis identified Streptococcus pneumoniae, Salmonella enterica, Staphylococcus aureus, Escherichia coli and Haemophilus influenzae as the major causes of bloodstream infections in African children [17]. The PCR test described here could be developed to detect these other organisms directly from blood samples.

In addition to the practical use of this assay for the qualitative analysis of field samples, the ability to perform real-time PCR for malaria directly from blood can 
be exploited in new technologies to bring molecular diagnostics for malaria to the point-of-care [18]. A number of technologies have been reported but they generally require an upstream module for DNA extraction $[3,19,20]$. Using the methodology described, this step can be omitted and samples can be immediately processed for diagnostic testing.

\section{Conclusions}

The methodology described here supports the amplification of gDNA by fluorescence-based real-time PCR directly from blood samples infected with malaria. The advantage of this assay is the elimination of the DNA extraction step, thereby facilitating high-throughput analysis of samples collected in the field using state-of-theart tools for the detection and characterization of Plasmodium infections.

\begin{abstract}
Acknowledgements
We thank Sandra Shokoples for laboratory assistance and Severiano Velazquez for field collection assistance. We are grateful to Dr. John Crabtree and Dr. Linda Pilarski for comments on the manuscript. The following reagents were obtained through the MR4: genomic DNA from Plasmodium knowlesi $\mathrm{H}$ strain and Plasmodium falciparum 3D7 malaria parasites contributed by D. J. Carucci. This work was supported by an Interdisciplinary Team Grant from the Alberta Heritage Foundation for Medical Research, Colciencias (contract RC 238-2007) and the Universidad de Antioquia.
\end{abstract}

\section{Author details}

${ }^{1}$ Department of Oncology, University of Alberta, Edmonton, Canada. ${ }^{2}$ Grupo Salud y Comunidad, Faculty of Medicine, Universidad de Antioquia, Medellín, Colombia. ${ }^{3}$ School of Public Health, University of Alberta, Edmonton, Canada.

${ }^{4}$ Provincial Laboratory for Public Health, Edmonton, Canada.

\section{Authors' contributions}

BJT and KAM performed the real-time PCR testing of blood samples and contributed equally to this work. AM provided dried blood spots from samples collected in the field and EA and OMA tested these samples by nested PCR. SKY and BJT designed the experiments and SKY wrote the manuscript. All authors read and approved the final manuscript.

\section{Competing interests}

The authors declare that they have no competing interests.

Received: 7 June 2011 Accepted: 19 August 2011

Published: 19 August 2011

\section{References}

1. Wilson PE, Alker AP, Meshnick SR: Real-time PCR methods for monitoring antimalarial drug resistance. Trends Parasitol 2005, 21:278-283.

2. Felger I, Genton B, Smith T, Tanner M, Beck HP: Molecular monitoring in malaria vaccine trials. Trends Parasitol 2003, 19:60-63.

3. Hawkes M, Kain KC: Advances in malaria diagnosis. Expert Rev Anti Infect Ther 2007, 5:485-495.

4. Al-Soud WA, Radstrom P: Purification and characterization of PCRinhibitory components in blood cells. J Clin Microbiol 2001, 39:485-493.

5. Radstrom P, Knutsson R, Wolffs P, Lovenklev M, Lofstrom C: Pre-PCR processing: strategies to generate PCR-compatible samples. $\mathrm{Mol}$ Biotechnol 2004, 26:133-146.

6. Fuehrer HP, Fally MA, Habler VE, Starzengruber P, Swoboda P, Noedl H: Novel nested direct PCR technique for malaria diagnosis using filter paper samples. J Clin Microbiol 2011, 49:1628-1630.
7. Kermekchiev MB, Kirilova LI, Vail EE, Barnes WM: Mutants of Taq DNA polymerase resistant to $P C R$ inhibitors allow DNA amplification from whole blood and crude soil samples. Nucleic Acids Res 2009, 37:e40.

8. Zhang Z, Kermekchiev MB, Barnes WM: Direct DNA amplification from crude clinical samples using a PCR enhancer cocktail and novel mutants of Taq. J Mol Diagn 2010, 12:152-161.

9. Trager W, Jensen JB: Human malaria parasites in continuous culture. Science 1976, 193:673-675.

10. Shokoples SE, Ndao M, Kowalewska-Grochowska K, Yanow SK: Multiplexed real-time PCR assay for discrimination of Plasmodium species with improved sensitivity for mixed infections. J Clin Microbiol 2009, 47:975-980.

11. Matisz CE, Naidu P, Shokoples SE, Grice D, Krinke V, Brown SZ, KowalewskaGrochowska K, Houston S, Yanow SK: Post-arrival screening for malaria in asymptomatic refugees using real-time PCR. Am J Trop Med Hyg 2011, 84:161-165.

12. Snounou G, Viriyakosol S, Zhu XP, Jarra W, Pinheiro L, do Rosario VE, Thaithong S, Brown KN: High sensitivity of detection of human malaria parasites by the use of nested polymerase chain reaction. Mol Biochem Parasitol 1993, 61:315-320.

13. Kamau E, Tolbert LS, Kortepeter L, Pratt M, Nyakoe N, Muringo L, Ogutu B, Waitumbi JN, Ockenhouse CF: Development of a highly sensitive genusspecific quantitative reverse transcriptase real-time PCR assay for detection and quantitation of Plasmodium by amplifying RNA and DNA of the 18S rRNA genes. J Clin Microbiol 2011, 49:2946-2953.

14. Rubio JM, Benito A, Roche J, Berzosa PJ, Garcia ML, Mico M, Edu M, Alvar J: Semi-nested, multiplex polymerase chain reaction for detection of human malaria parasites and evidence of Plasmodium vivax infection in Equatorial Guinea. Am J Trop Med Hyg 1999, 60:183-187.

15. de Monbrison F, Angei C, Staal A, Kaiser K, Picot S: Simultaneous identification of the four human Plasmodium species and quantification of Plasmodium DNA load in human blood by real-time polymerase chain reaction. Trans $R$ Soc Trop Med Hyg 2003, 97:387-390.

16. Rougemont M, Van Saanen M, Sahli R, Hinrikson HP, Bille J, Jaton K: Detection of four Plasmodium species in blood from humans by $18 \mathrm{~S}$ rRNA gene subunit-based and species-specific real-time PCR assays. Clin Microbiol 2004, 42:5636-5643.

17. Reddy EA, Shaw AV, Crump JA: Community-acquired bloodstream infections in Africa: a systematic review and meta-analysis. Lancet Infect Dis 2010, 10:417-432

18. Atrazhev A, Manage DP, Stickel AJ, Crabtree HJ, Pilarski LM, Acker JP: In-gel technology for PCR genotyping and pathogen detection. Anal Chem 2010, 82:8079-8087.

19. Gascoyne P, Satayavivad J, Ruchirawat M: Microfluidic approaches to malaria detection. Acta Trop 2004, 89:357-369.

20. Yager P, Domingo GJ, Gerdes J: Point-of-care diagnostics for global health. Annu Rev Biomed Eng 2008, 10:107-144.

doi:10.1186/1475-2875-10-244

Cite this article as: Taylor et al: Real-time PCR detection of Plasmodium directly from whole blood and filter paper samples. Malaria Journal 2011 $10: 244$

\section{Submit your next manuscript to BioMed Central and take full advantage of:}

- Convenient online submission

- Thorough peer review

- No space constraints or color figure charges

- Immediate publication on acceptance

- Inclusion in PubMed, CAS, Scopus and Google Scholar

- Research which is freely available for redistribution

Submit your manuscript at www.biomedcentral.com/submit
C Biomed Central 